\title{
Inhibition of Conjugal Transfer of R Plasmids by Nitrofurans
}

\author{
By Y. MICHEL-BRIAND* AND J. M. LAPORTE \\ Laboratoire de Bactériologie-Virologie, Faculté de Médecine, Place Saint-Jacques, \\ 25030 Besançon, France
}

(Received 7 January 1985; revised 22 April 1985)

\begin{abstract}
Nifurzide is a nitrofuran with antibacterial activity. As nitrofurans have been reported to interact with DNA, we tested the ability of nifurzide to inhibit plasmid transfer. Inhibition of plasmid transfer between Escherichia coli strains was obtained for ten plasmids belonging to nine incompatibility groups. The same effect was observed when plasmid RP4 was harboured in six different members of the Enterobacteriaceae. Inhibition depended on the reduction of the $-\mathrm{NO}_{2}$ group of nifurzide and was obtained with four other nitrofuran derivatives.
\end{abstract}

\section{INTRODUCTION}

Bacterial resistance to antibiotics mediated by plasmid genes is widespread. Some compounds, namely acridine derivatives, 'cure' or eliminate $\mathrm{R}$ plasmids (Watanabe \& Fukasawa, 1961), while a few antibiotics interfere with maintenance or transfer of $\mathrm{R}$ plasmids, namely rifampicin (Fenwick \& Curtiss, 1973b), nalidixic acid (Chabbert et al., 1969; Fenwick \& Curtiss, 1973a) and its derivatives (Nakamura et al., 1976), clindamycin (Coats \& Roeser, 1977), trimethoprim (Pinney \& Smith, 1972) and nitrofuran (Shenderov, 1971). Most of these substances seem to exert their antibacterial effect by interfering, directly or indirectly, with DNA replication, and this is true for nitrofuran (Iida \& Koike, 1977). Here we report that several nitrofurans inhibit plasmid transfer. A preliminary report has been published (MichelBriand \& Laporte, 1982).

\section{METHODS}

Bacterial strains. Escherichia coli K12 (J53) (met-63, pro-22) and UB1139 (leu met thy nal) were obtained respectively from N. Datta (Royal Postgraduate Medical School, Hammersmith Hospital, London, UK) and P. M. Bennett (Dept of Bacteriology, University Walk, Bristol, UK). E. coli AB1 157 thr-I leu-6 thi-6 lac Y1 galK2 ara$14 x y l-5$ mtl-1 proA2 argE3 str-31 tsx-33 $n f s^{+} B^{+}$and its $n f s A B$ mutant, NFR502, were provided by D. R. McCalla (Dept of Biochemistry, McMaster University, Hamilton, Ontario, Canada). Salmonella typhimurium LT2-M329 $\operatorname{Trp}^{-}$, Shigella sonnei 7823, Klebsiella pneumoniae NCTC 234 and Serratia marcescens SM were obtained from N. Datta and Proteus mirabilis PMI (nad str) from P. M. Bennett. Pseudomonas aeruginosa PAO8 (met-28 ill -202 str-l) was the strain of Isaac \& Holloway (1968) and Pseudomonas aeruginosa PAO2635 (trp-54 rif-3 fon-10I) was from V. Stanisich (Dept of Microbiology, La Trobe University, Bundoora, Victoria, Australia).

Plasmids. R386 (Tc) (IncFI), R446b (Sm, Tc) (IncM), Sa (Sm, Km, Cm, Su) (IncW) and R6K (Cb, Sm) (IncX) were gifts from N. Datta; pIP24 (Tc) (IncFII) and R64 (Sm, Tc) (IncI1) were obtained from P. Courvalin (Institut Pasteur, Paris, France); RGN238 (Ap, Sm, Tc, Cm, Su) (IncFI) was from M. Matthew (Glaxo Holdings Ltd, London, UK): N3 (Sm, Tc. Su) (IncN) was from E. L. Lederberg (Dept of Medical Microbiology, Stanford University, Stanford, Calif., USA): RP4 (Km, Nm, Tc, Ap) (IncP) was from P. M. Bennett; pYMBl (Cb, Sm, Sp, $\mathrm{Nm}, \mathrm{Pm}, \mathrm{Lv}, \mathrm{Rm}, \mathrm{Gm}, \mathrm{Ss}, \mathrm{Cm}, \mathrm{Tc}, \mathrm{Su}$ ) (IncPI) was from this laboratory (Michel-Briand et al., 1981).

Media and antibiotics. A semi-solid medium [heart-brain infusion (Institut Pasteur Production) with $0 \cdot 08 \%(w / v)$ agar] layered on a solid medium (Mueller-Hinton, Institut Pasteur Production) was used to enumerate viable bacteria. Antibiotics were incorporated as appropriate at the following concentrations: carbenicillin $(\mathrm{Cb})$ $500 \mu \mathrm{g} \mathrm{ml}^{-1}$; cloxacillin (Cl) $800 \mu \mathrm{g} \mathrm{ml}^{-1}$ (Beecham-Sevigné, Paris); nalidixic acid (Nal) $100 \mu \mathrm{g} \mathrm{ml}^{-1}$ (Winthrop,

Abbretiation: MITC, minimum inhibition of transfer concentration. 
Clichy, France); rifampicin (Rf) $100 \mu \mathrm{g} \mathrm{ml}^{-1}$ (Lepetit, Neuilly-sur-Seine, France); tetracycline (Tc) 40 and $100 \mu \mathrm{g} \mathrm{m}^{-1}$ (Pfizer, Orsay, France); chloramphenicol $(\mathrm{Cm}) 50 \mu \mathrm{g} \mathrm{ml}^{-1}$ (Roussel, Paris); ampicillin (Ap) $100 \mu \mathrm{g} \mathrm{ml}^{-1}$ (Bristol, Paris); novobiocin (No) (Theraplix, Paris). Suitable inhibitory concentrations of nifurzide (Anphar-Rolland, Chilly-Mazarin, France) were determined for each conjugation. The compound was dissolved in dimethylsulphoxide/water to give a final concentration of $1.2 \%(\mathrm{v} / \mathrm{v})$ dimethylsulphoxide (DMSO) in the culture medium. Minimum inhibitory concentrations (MIC) were determined according to Thrupp (1980). Other nitrofuran derivatives used were: methylfuradoin (1-[[(5-methyl-2-furanyl)methylene $]$ amino $]-2,4$-imidazolidinedione) and hydrofuradoin (1-[[(2-furanyl)methylene]amino]-2,4-imidazolidinedione) (generously provided by $\mathbf{M}$. Dershwitz, Dept of Pharmacology, Northwestern University, Medical and Dental Schools, Chicago, USA); and furazolidone and nitrofurantoin, methylmercadone and hydroxymethylnitrofurantoin (gifts from Oberval, Fumouze and Arsac laboratories respectively).

Bacterial matings. Bacteria were grown in heart-brain infusion broth at $37^{\circ} \mathrm{C}$ in a rotary shaker for $3 \mathrm{~h}$; matings were performed between $10^{8}$ donor bacteria $\mathrm{ml}^{-1}$, harbouring the plasmid under test, in the exponential growth phase, and $10^{9}$ recipient bacteria $\mathrm{ml}^{-1}$ in a final volume of $4.5 \mathrm{ml}$ heart-brain infusion broth. Donor and recipient viable counts were made for each mating. Most matings were between $E$. coli J53 donor, and $E$. coli UB1139 recipient strains. Mating mixtures were incubated in test tubes in a $37^{\circ} \mathrm{C}$ water bath, without shaking.

In preliminary experiments mating mixtures were incubated for $3 \mathrm{~h}$ with a range of nifurzide concentrations $(30,45,60,75,90,100,120,140,180,220$ and $440 \mu \mathrm{M})$. The lowest concentration that inhibited the appearance of transconjugants and gave a less than 10-fold decrease of donor or recipient bacteria at $3 \mathrm{~h}$ was taken as the 'minimum inhibition of transfer concentration' (MITC).

Nifurzide at the MITC was then used in kinetic studies of plasmid conjugation. Transconjugants were assayed after $5,10,15,20,25,30,40,60 \mathrm{~min}$ and $2 \mathrm{~h}$. One control mating without nifurzide, and another with the solvent $\operatorname{DMSO}(1 \cdot 2 \%, \mathrm{v} / \mathrm{v})$ alone were always done in parallel. After the appropriate incubation the mating mixtures were shaken vigorously for $15 \mathrm{~s}$, and then transconjugants were selected by inoculating a dilution of the mating mixture onto $5 \mathrm{ml}$ semi-solid medium containing appropriate selective agents (e.g. Cb + Nal for J53(RP4) $\times$ UB1139). This was layered onto solid medium containing the same antibiotics. Transconjugant colonies were counted after $24 \mathrm{~h}$ incubation at $37^{\circ} \mathrm{C}$. Donor and recipient counts were obtained by plating samples of the mating mixture on an appropriate selective medium.

The transfer frequency was defined as the ratio of transconjugants to donors in a particular volume of mating mixture.

Matings between $E$. coli J53(RP4) and E. coli UB1139 were done more than 20 times. In all experiments a decrease in transfer frequency of $10^{3}$ to $10^{4}$ was always found. Experiments with other donor strains were done no more than twice, but always with a control without nifurzide. Nine different concentrations were tested for each mating.

\section{RESULTS AND DISCUSSION}

Kinetics of appearance of transconjugants between E. coli J53(RP4) and UB1139

Conjugation without nifurzide. Under our experimental conditions, transconjugants were detected as soon as $5 \mathrm{~min}$ after the beginning of the mating for RP4. The number of transconjugants increased for $2 \mathrm{~h}$ (at this time, the transfer frequency was $10^{-3}$ ). In a medium containing DMSO $(1.2 \%)$ the kinetics of plasmid transfer were unaltered.

Conjugation in the presence of nifurzide at the MITC. The MITC $\left(60 \mu \mathrm{M}\right.$, i.e. $\left.20 \mu \mathrm{g} \mathrm{ml}^{-1}\right)$ was higher than the subinhibitory concentration obtained during the determination of the MIC (respectively 2.3 and $7 \cdot 1 \mu \mathrm{M}$, i.e. 0.8 and $2.4 \mu \mathrm{g} \mathrm{ml}^{-1}$, after $7 \mathrm{~h}$ incubation for donor and recipient respectively) probably because in this determination only one bacterial type was tested and at a much lower cell density $\left(10^{6}\right.$ bacteria $\left.\mathrm{ml}^{-1}\right)$ than that used during the matings. No transconjugants were obtained from matings of up to $3 \mathrm{~h}$ when nifurzide was added at the beginning of the mating. Furthermore, the addition of nifurzide (to $60 \mu \mathrm{M}$ ) 20, 40,60, $90 \mathrm{~min}$ after mixing donor and recipient cultures prevented further increase in the number of transconjugants obtained.

Similar results were obtained with nine other plasmids (R386, R446b, Sa, R6K, pIP24, R64, RGN238, N3, pYMB1) belonging to eight incompatibility groups, and also with four other nitrofuran derivatives (furazolidone, nitrofurantoin, hydroxymethylnitrofurantoin and methylmercadone). 
Table 1. Matings between different donor bacteria harbouring RP4 and E. coli UB1139

\section{Donor strain}

Escherichia coli J53(RP4)

Salmonella typhimurium LT2(RP4)

Shigella sonnei 7823(RP4)

Proteus mirabilis PM1(RP4)

Klebsiella pneumoniae 234(RP4)

Serratia marcescens SM(RP4)

\begin{tabular}{|c|c|c|}
\hline \multicolumn{3}{|c|}{ Transfer frequency* } \\
\hline $\begin{array}{l}\text { Without } \\
\text { nifurzide }\end{array}$ & $\begin{array}{c}\text { With } \\
\text { nifurzide }\end{array}$ & $\begin{array}{c}\text { MITC } \dagger \\
(\mu \mathrm{M})\end{array}$ \\
\hline $2 \times 10^{-3}$ & $<1 \times 10^{-7}$ & 60 \\
\hline $2 \times 10^{-4}$ & $<5 \times 10^{-7}$ & 80 \\
\hline $3 \times 10^{-4}$ & $<1 \times 10^{-7}$ & 60 \\
\hline $2 \times 10^{-4}$ & $<6 \times 10^{-8}$ & 60 \\
\hline $4 \times 10^{-5}$ & $<5 \times 10^{-8}$ & 60 \\
\hline $5 \times 10^{-4}$ & $<1 \times 10^{-7}$ & 45 \\
\hline
\end{tabular}

* Transfer frequency at $3 \mathrm{~h}$ after the beginning of the mating, calculated as (number of transconjugants at $3 \mathrm{~h}) /$ (number of donors at the beginning of the mating).

$\dagger$ The lowest concentration of nifurzide which inhibited plasmid transfer (as described in Methods) and which was used in the matings.

\section{Conjugation between different Enterobacteriaceae harbouring RP4 and E. coli UB1139}

Nifurzide at the MITC, determined as described previously, inhibited plasmid transfer from all six strains of Enterobacteriaceae studied (Table 1). In contrast, no inhibition of transfer was observed between two Pseudomonas aeruginosa strains (PAO8 and PAO2635) intrinsically resistant to nifurzide (MIC $>440 \mu \mathrm{M}$ ).

\section{Nature of chemical group involved in the plasmid transfer inhibition}

Three very closely related compounds, nitrofurantoin (an antibacterial compound), hydrofurantoin and methylfurantoin (both devoid of any antibacterial activity, and where the $-\mathrm{NO}_{2}$ group of nitrofurantoin is replaced by a hydroxyl and a methyl group respectively; Dershwitz \& Novak, 1980) were tested for their effect on RP4 transfer. Using the same molar concentration of each compound $(100 \mu \mathrm{M})$, a decrease in the yield of transconjugants was seen only with nitrofurantoin. Moreover the $-\mathrm{NO}_{2}$ group of this compound must be in the reduced state for it to inhibit transfer, for inhibition occurred if the donor strain (E. coli AB1157) contained a high level of reductase I but was almost absent with a donor strain (E. coli NFR502) lacking reductase $\mathrm{I}$.

The lack of progeny from conjugations in the presence of nifurzide was not due to plasmid curing, since when E. coli J53(RP4) was exposed to subinhibitory concentrations of this compound for $18 \mathrm{~h}$ at $37^{\circ} \mathrm{C}$, no loss of plasmid was observed (over 8000 colonies tested). The same results were found at the MITC (exposure for $3 \mathrm{~h}$ ). Furthermore, nifurzide did not seem to act by affecting the bacterial surface or sex pili in some way, because there was no alteration of attachment of bacteriophages 434, TU1 A and K10 (specific for OmpC, OmpF and LamB outer membrane porins respectively), nor of RP4 bacteriophage (specific for RP4 plasmid pili) (results not shown). In addition, because conjugation between two Pseudomonas aeruginosa strains resistant to nitrofuran by impermeability was not inhibited, we conclude that nifurzide probably enters the cell to exert its action.

Lastly, $g y r A$ and $g y r B$ mutations failed to confer resistance to nifurzide (results not shown).

In conclusion, nifurzide has been shown to inhibit the transfer of plasmids belonging to different incompatibility groups, between different members of the Enterobacteriaceae. Inhibition was due to the reduced form of the compound. However, it was not possible to distinguish between an inhibition due to a specific effect on plasmid replication and a less specific alteration of the metabolic activity of the host bacteria. Nonetheless, it is interesting to speculate from the experiments of Wagner et al. (1977), concerning the induction of $\beta$ galactosidase in the presence of nitrofurantoin, that a new RNA involved in plasmid replication is not translated while a nitrofuran derivative is present. 
We wish to thank N. Datta both for providing most of the enterobacterial strains and plasmids used, and for advice, and P. M. Bennett, P. Courvalin, E. L. Lederberg, D. R. McCalla and V. Stanisich for providing particular strains or plasmids. M. Dershwitz is thanked for gifts of furadoin derivatives. Laboratoires Arsac, Beecham, Bristol, Fumouze, Lepetit, Lipha, Oberval, Pfizer, Roussel, Theraplix, Winthrop, are acknowledged for generous gifts of antibiotics.

\section{REFERENCES}

Chabbert, Y., Baudens, J. G. \& Bouanchaud, D. H (1969). Medical aspects of transferable drug resistance. In Bacterial Episomes and Plasmids (Ciba Foundation Symposium), pp. 227-239. Edited by G. E. W. Wolstenholme \& M. O'Connor. London: Churchill.

CoATs, J. H. \& Roeser, J. (1977). In vivo inhibition of R-factor transfer by clindamycin and its analogues. Journal of Antimicrobial Chemotherapy 3 (suppl. C), 53- 58.

Dershwitz, M. \& Novak, R. F. (1980). Lack of inhibition of glutathione reductase by unnitrated derivatives of nitrofurantoin. Biochemical and Biophysical Research Communications 92, 1313-1319.

Fenwick, R. G. \& Curtiss, R. (1973a). Conjugal deoxyribonucleic acid replication by Escherichia coli K-12: effect of nalidixic acid. Journal of Bacteriology 116, 1236-1246.

Fenwick, R. G. \& Curtiss, R. (1973b). Conjugal deoxyribonucleic acid replication by Escherichia coli $\mathrm{K}-12$ : effect of chloramphenicol and rifampicin. Journal of Bacteriology' 116, 1224-1235.

IIDA, K. \& KoIKE, M. (1977). Effect of dihydroxymethylfuratrizine on cell division of Escherichia coli. Microbiology and Immunology 21, 481-494.

ISAAC, J. H. \& HollowaY, B. W. (1968). Control of pyrimidine biosynthesis in Pseudomonas aeruginosa. Journal of Bacteriology 96, 1732-1741.

Michel-BRiand, Y. \& Laporte, J. M. (1982). Inhibition de la diffusion de plasmides par un dérivé des nitrofuranes. Comptes rendus de l'Académie des Sciences de Paris 294, série III, 249-252.

Michel-Briand, Y., Dupont, M. J., ChardonLoRIAUX, I. \& JoUvenot, M. (1981). Isolation of an antibiotic multiresistance plasmid from Pseudomonas aeruginosa. Journal of Antimicrobial Chemotherapy 7, 371-378.

Nakamura, S., Inoue, S., Shimizu, M., Iyobe, S. \& MitsuHaSHI, S. (1976). Inibition of conjugal transfer of $\mathrm{R}$ plasmids by pipemidic acid and related compounds. Antimicrobial Agents and Chemotherapy 10, 779-785.

PinNey, R. J. \& SMITH, J. T. (1972). Elimination of an R-factor by trimethoprim. Journal of Pharmacy and Pharmacolog. 24, suppl., 126P.

SHenderov, B. A. (1971). Effect of 5-nitrofuran derivatives on transmission of drug refractoriness by conjugation. Zhurnal mikrobiologii, epidemiologii $i$ immunologii 48, 77-81. (In Russian)

THRUPP, L. D. (1980). Susceptibility testing of antibiotics in liquid media. In Antibiotics in Laboratory Medicine, pp. 73-113. Edited by V. Lorian. Baltimore: Williams \& Wilkins.

Wagner, E., Schweiger, M., Ponta, H. \& Herrlich, P. (1977). Messenger-selective inhibitor for the initiation of translation in Escherichia coli: nitrofurantoin. FEBS Letters 83, 337-340.

Watanabe, T. \& Fukasawa, T. (1961). Episomemediated transfer of drug resistance in Enterobacteriaceae. II. Elimination of resistance factors with acridine dyes. Journal of Bacteriology 81, 679-683. 